\title{
Lyon $7^{\mathrm{e}}-34$ bis rue du Père Chevrier
}

\section{Catherine Bellon}

URL : http://journals.openedition.org/adlfi/15414

ISSN : 2114-0502

Éditeur

Ministère de la culture

Référence électronique

Catherine Bellon, « Lyon $7^{\mathrm{e}}$ - 34bis rue du Père Chevrier 》, ADLFI. Archéologie de la France - Informations [En ligne], Rhône-Alpes, mis en ligne le 26 août 2015, consulté le 19 avril 2019. URL : http://

journals.openedition.org/adlfi/15414

Ce document a été généré automatiquement le 19 avril 2019

(c) Ministère de la Culture et de la Communication, CNRS 


\section{Lyon $7^{\mathrm{e}}-34$ bis rue du Père Chevrier}

\section{Catherine Bellon}

Code INSEE de la commune : 69387

Lien Atlas (MCC) :

http://atlas.patrimoines.culture.fr/atlas/trunk/index.php?

ap_theme=DOM_2.01.02\&ap_bbox=4.772;45.707;4.899;45.808

1 Un projet de construction d'un ensemble immobilier sur deux niveaux de sous-sol a conduit l'Inrap à intervenir sur une zone de $658 \mathrm{~m}^{2}$ au 34B rue du Père Chevrier. Cette campagne de diagnostic s'est déroulée du 11 au 15 mars 2013, permettant à deux archéologues de sonder $16,43 \%$ du terrain accessible (ouverture des sondages), soit un grand sondage avec gradin de sécurité et un puits.

2 Ces deux sondages n'ont livré aucun vestige ; seuls des remblais contemporains et une couche caractérisée dans ce secteur comme niveau agricultural antique ont été repérés. Sous ces couches anthropisées ont été mis au jour des alluvions fines sableuses et le cailloutis rhodanien, mis en place par tressage durant la première moitié du Subboréal (162,60 m).

\section{INDEX}

Index géographique : Rhône-Alpes, Rhône (69), Lyon 7e arrond. (69387)

operation Opération préventive de diagnostic (OPD), 2013 - n OA : 2211176 
AUTEURS

CATHERINE BELLON

Inrap 